shelf. I will refer to it when dealing with commissioners, and will lend it to interested commissioners and to specialist registrars who are applying for consultant posts. I am sure that it will best be read in conjunction with the NSF. However, hope that the authors will urgently update the handbook, and that they will now provide us with a fresh volume that explicitly takes into account the NSF. If they do so, then we will have a truly powerful operational handbook, and one which will stand us in good stead for several years to come.

Mark Berelowitz Consultant Child and Adolescent Psychiatrist, Royal Free Hampstead NHS Trust, London

\title{
miscellany
}

\section{The Mental Health Act 1983 Video for Deaf People}

This new video, produced in British Sign Language (BSL), is aimed primarily at deaf people whose first or preferred language is BSL, to provide information for those who have a mental health illness/problem. Within the mental health field, there are very few professionals who use BSL. Therefore, deaf people do not consistently get full information in their first or preferred language. This video is a breakthrough in allowing deaf people access to vital information, such as: what would happen if they were detained, and their rights under the Mental Health Act 1983; medication; and how long their stay in hospital would be. The video will also help widen the understanding of hearing professionals who may have little or no knowledge of deaf issues, and in this respect, it describes how to book interpreters, shows strong deaf role models to promote wider deaf awareness and explains communication tactics, along with other vital information.

This video is an extremely positive step forward; however, there is still a long way to go. There are many areas of information that deaf people have difficulty in accessing. It is hoped that the video will encourage professionals to think about how to get involved in making positive changes in the healthcare of deaf people.

To purchase the video in VHS or DVD format please contact Forest Bookshops (www.forestbooks.com; tel/minicom: 01594833 858). For further information please contact the British Society for Mental Health and Deafness (BSMHD): www.bsmhd.org.uk

\section{The Royal College of Psychiatrists' Eastern Division Research Prize}

The College Eastern Division Research Prize was created in 2002 to encourage and reward research in the Eastern Division. It is open to all doctors who are consultants working within the Eastern Division. The closing date for submissions is 1 July 2005. The entries will be judged by three examiners to include the chairman, one executive member and one coopted member. The prize is $f 500$ plus a certificate and will be awarded in November 2005. There will be the opportunity for the researcher to present his/ her work at a later academic programme. For further information on the prize please contact the chairman of the Eastern Division, Dr Christopher Mayer (e-mail: christopher.mayer@lhp.nhs.uk).

\section{forthcoming events}

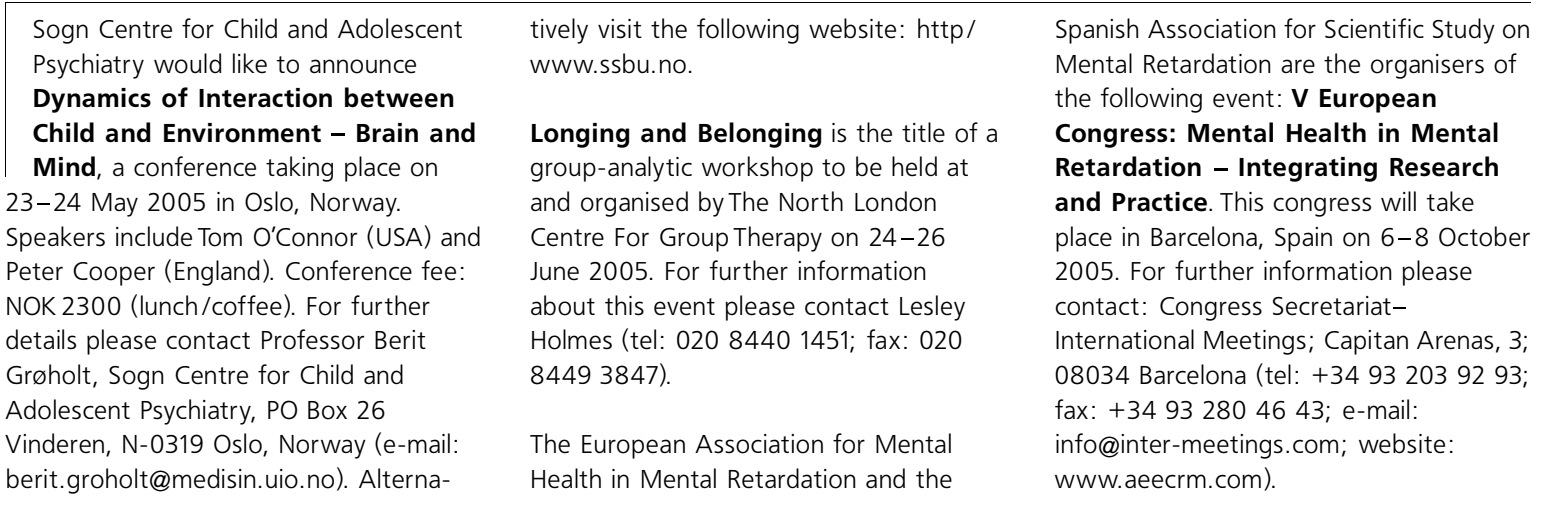

